\title{
Rita Hayworth murió sin saber quién era. Fronteras del conocimiento y del relato en La estirpe del silencio, de Sandra Lorenzano
}

Resumen: Este artículo analiza La estirpe del silencio, novela de Sandra Lorenzano que recrea la vida de Rita Hayworth, a partir de tres fronteras: la frontera geográfica, la frontera de la memoria, la frontera del lenguaje. Estas marcan los límites no solo entre territorios, sino también entre espacios y conceptos como el progreso y el atraso, la civilización y la violencia, la realidad y la ficción. Es decir: los límites del conocimiento y del relato.

Palabras clave: Rita Hayworth, alzhéimer, biografía, ficción, Sandra Lorenzano

Rita Hayworth died without knowing who she was. Frontiers of knowledge and story in Sandra Lorenzano's La estirpe del silencio

Abstract: This article analyzes La estirpe del silencio, Sandra Lorenzano's novel, that recreates the life of Rita Hayworth, from three borders: geographical border, the border of memory, language border. These mark the boundaries not only between territories, but also between spaces and concepts as progress and backwardness, civilization and violence, reality and fiction. That is, the limits of knowledge and story.

Keywords: Rita Hayworth, Alzheimer, Biography, Fiction 


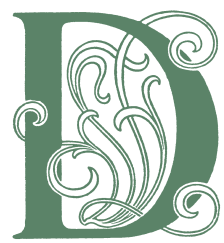

os días después de la muerte de Rita Hayworth, el diario español El País daba la noticia aludiendo a «una enfermedad del cerebro» (El País 1987) ${ }^{1}$ como la causa del fallecimiento de la estrella de Hollywood. Esta enfermedad, en concreto, se definía como «una especie de senilidad precoz» aunque en el cuerpo de la noticia se detallaba el nombre, extraño por aquel entonces. El New York Times, sin embargo, el mismo 16 de mayo de 1987 en que desapareció la actriz, ponía en valor el esfuerzo de su hija Princess Yasmin Aga Khan por dar a conocer el nombre de la enfermedad que padecía su madre: alzhéimer ${ }^{2}$. El diario colombiano El Tiempo explicaría más tarde cómo solo tras su muerte, se le pudo diagnosticar la enfermedad, pero no dejaba de representarla con un halo de misterio a la vez trágico y profundo: «entre los muchos síntomas de esta enfermedad los pacientes no saben reconocer el día de la noche, pierden la memoria y su identidad propia» (García Marrder, 1994) de modo que llegaron a titular la noticia de la siguiente manera: «Rita Hayworth murió sin saber quién era» ${ }^{3}$.

«Saber quién era» es quizás el objetivo de las diferentes historias que componen La estirpe del silencio (2015), la novela de Sandra Lorenzano. A partir de la enfermedad de Rita Hayworth, este personaje en primera persona buceará en la bruma de su memoria para revivir su pasado, desde las escenas de Gilda que la hicieron famosa, hasta el alcoholismo de los últimos años, pasando por los traumas de su infancia, cuando se llamaba Margarita Carmen Cansino y su padre le hacía cruzar la frontera entre Estados Unidos y México para exhibirla como bailarina en los bares de la frontera mexicana. Junto a la historia de la diva norteamericana, dos historias ficcionales se entrecruzarán con la misma voluntad: «saber quién era». En la primera de ellas, Anette atesorará durante toda su vida las últimas palabras de su hermana: «somos las guardianas de la memoria» (Lorenzano, 2015: 19) y rememorará la muerte de sus padres en París, el viaje a México en busca de una vida mejor donde su hermana esperaba casarse, cómo obligaron a su hermana a prostituirse y cómo ella, tras un breve paso por un convento en León, fue acogida por una

\footnotetext{
Cf. http://elpais.com/diario/1987/05/16/cultura/548114403_850215.html

2 "Since 1981 the actress had been under the care of her second daughter, Princess Yasmin Aga Khan, who by publicizing her mother's tragic illness had drawn national and international attention to Alzheimer's disease, about which little was known until recent years". (Kerbs, 1987)

3 Cf. http://www.eltiempo.com/archivo/documento/MAM-226527
} 
familia de emigrantes gallegos en Tijuana. En la segunda, Irene se valdrá de fotos y documentos para intentar averiguar quién era su abuela Claire y por qué se separó de su madre Noëlle, recientemente fallecida.

Estas tres historias se articulan en torno a la misma voluntad de conocer la identidad (propia o ajena). Se construyen, pues, como relatos que intentan cruzar el umbral de un desconocimiento o de un desconcierto para poner en orden el mundo conocido. La exploración del pasado será una operación de conquista en la que la literatura será el arma con que desbrozar la maraña de la memoria y construir ese nuevo espacio explicativo de la propia identidad. Ese territorio de batalla estará delimitado por tres fronteras que se deberán franquear para reconstruir las historias: la frontera geográfica en primer lugar, para delimitar de dónde proviene la identidad, qué conflictos arrastra ligados al desarraigo o a la expatriación; la frontera de la memoria en segundo lugar, para observar qué permanece de nuestro pasado, cuáles son las interferencias con la imaginación y cuáles son los límites de nuestro conocimiento; la frontera del lenguaje en tercer lugar, para intentar responder a la consabida pregunta que se plantea en la encrucijada de todo relato: ¿de qué manera es posible contar el pasado traumático?, ¿se trata de desvelar una identidad dada?. ¿o acaso no es la identidad precisamente la construcción -ficcional- de un relato sobre nosotros mismos, nuestro entorno y nuestra historia?

\section{FRONTERAS GEOGRÁFICAS}

En los años veinte la ciudad de Tijuana se convirtió en una ciudad turística y recreativa de primer orden. Al calor de la creciente industria cinematrográfica de Hollywood y merced al imperio de la Ley Seca vigente en California hasta 1933, la ciudad mexicana se transformó en una ciudad que contaba con restaurantes, salas de fiesta, hoteles lujosos, campos de golf, hipódromo y hasta pista de aterrizaje. En este entorno de lujo y fama, florecieron los negocios turbios, la criminalidad y eran frecuentes los asesinatos, desapariciones, las visitas de los gángsters o la prostitución de menores; quizás Ciudad Juárez sea hoy la trágica actualización de este espacio de frontera, recreado por Huesos en el desierto (2002) de Sergio González Rodríguez, o la apócrifa ciudad de Santa Teresa en 2666 (2004) de Roberto Bolaño, aunque en este 
caso no sea un espacio en expansión debido la diversión de los casinos y los clubes de lujo, sino espoleado por la industria maquiladora, en el que predominan unos costos de producción más bajos que al otro lado de la frontera y la acumulación de mano de obra barata, especialmente de mujeres jóvenes a partir de los 16 años (Cravey 1998).

La frontera norteamericana, y más concretamente Tijuana a partir de los años veinte, representaría entonces los límites no solo entre dos países, sino también entre dos mundos: entre la moralidad puritana del norte y la satisfacción de los bajos instintos del sur, la rectitud y la diversión, la legalidad y la ilegalidad.

Los pocos metros que separaban el restaurante de la entrada principal del casino lo habían convertido en el lugar favorito de los empleados. Había ruido, gente y conversaciones durante todo el día.

- Dicen que quieren construir un hipódromo.

- ¿Dentro de Agua Caliente?

-Si ya hay pista de aterrizaje, ¿por qué no?

Y claro, uno de los entretenimientos principales era tratar de ver a las estrellas de la naciente industria de Hollywood.

- ¡Ayer estuvo Dolores del Río! ¡Divina! Con Gibbons que no la deja ni a sol ni a sombra.

- Después de las escenas de Aves del paraíso, lo entiendo. Las miradas de Joel McCrea no son para dejar tranquilo a ningún marido (Lorenzano, 2015: 132-33).

En este lugar confluirán las tres historias de la novela. Rita Hayworth debutará como bailarina a los trece años con el nombre de Margarita Carmen Cansino. Su padre, un bailaor de origen andaluz, la obligará a cruzar la frontera todos los días y la exhibirá como bailarina y la ofrecerá a magnates y clientes como esclava sexual. Este aspecto real y controvertido de la biografía

4 Elena Poniatowska insistiría en la denuncia de violaciones, desapariciones y asesinatos de mujeres y la responsabilidad de las autoridades a la hora de esclarecer los crímenes en un artículo aparecido en $\mathrm{La}$ Jornada el 26 de noviembre de 2002 titulado: "Ciudad Juárez, matadero de mujeres". 
de la estrella de Hollywood se recrea en los monólogos interiores que la actriz despliega en la novela, alejada en su madurez de los escenarios y recluida en la pequeña localidad argentina de Puerto Madryn, cuyas corrientes de aire frente al mar de la Patagonia le habían recomendado para detener el avance del alzhéimer.

«Baila, Maggie, baila». «Solo tengo trece años, papá. A los trece las niñas son niñas. No bailan en antros perdidos al otro lado de la frontera». No se lo dije. $\mathrm{Ni}$ a los trece, ni después. Zapateo, me contoneo, porque eso es lo que él quiere. Alcanzo a ver las manos viejas y manchadas de los hombres. Las uñas amarillas del cigarro. Las voces estridentes. Él me mira satisfecho. Yo me humedezco los labios. Como si fuera una más de las mujeres que le coquetean en la calle. «Pero solo tengo trece años, papá». «Mamá estará contenta porque llevaremos dinero a casa. ¿No quieres que mamá esté contenta, acaso?» (Lorenzano, 2015: 36-37).

Así pues, Tijuana pasará de ser la ciudad de la diversión a la ciudad del crimen, en paralelo a la experiencia de la segunda historia..Los padres adoptivos de Anette habían llegado a México como emigrantes gallegos, atraídos por el crecimiento económico del país y la esperanza de hacer fortuna:

- Alguien nos había contado a mi mujer y a mí que parecía que a esta parte del país le habían puesto motores. Hacía poco que Tijuana y Mexicali habían sido fundadas como ciudades y necesitaban edificios y estaciones de tren y casas, y necesitaban gente que construyera.

-Y si eran ingenieros, mejor (Lorenzano, 2015: 203).

El norte del país atraía no solo inversión extranjera, sino una fuerte migración. Sin embargo, esta promesa del crecimiento económico y de ciudad desarrollada a partir de cálculos de ingeniería, urbanismo y tecnología del siglo XX no se podrá desprender de ese pecado original ligado al juego, al alcohol y a la prostitución. De hecho, al local donde baila la pequeña Margarita Cansino llegarán toda suerte de tipos infames, entre los que se encuentran Eduardo Cansino, el comisario Quiroz o el cura Taylor, quien se escabuye hacia los baños de la mano de Axel Márquez y Jimmi Saviano, los dos apuestos jóvenes de la escuela secundaria de Chula Vista y estrellas del equipo de fútbol americano del colegio. Homosexualidad, prostitución, abusos, el cura Taylor acabará asesinado en extrañas circunstancias. 
La base de la Modernidad, según Marshall Berman (1988) es esta: la contradicción entre el avance económico y el retroceso humano, entre la idea de progreso y la frustración de sus esperanzas, entre la concepción del bien y su perversión. Y Berman acude a Marx, uno de los grandes teóricos de la Modernidad, para renovar esta idea en pleno siglo XX:

Hoy día, todo parece llevar en su seno su propia contradicción. Vemos que las máquinas, dotadas de la propiedad maravillosa de acortar y hacer más fructífero el trabajo humano provocan el hambre y el agotamiento del trabajador. Las fuentes de riqueza recién descubiertas se convierten, por arte de un extraño maleficio, en fuentes de privaciones. [...] El dominio del hombre sobre la naturaleza es cada vez mayor; pero, al mismo tiempo, el hombre se convierte en esclavo de otros hombres o de su propia infamia. Hasta la pura luz de la ciencia parece no poder brillar más que sobre el fondo tenebroso de la ignorancia. Todos nuestros inventos y progresos parecen dotar de vida intelectual a las fuerzas materiales, mientras que reducen a la vida humana al nivel de una fuerza material bruta. Este antagonismo entre la industria moderna y la ciencia, por un lado, y la miseria y la decadencia, por otro; este antagonismo entre las fuerzas productivas y las relaciones sociales de nuestra época es un hecho palpable, abrumador e incontrovertible ${ }^{5}$ (Marx, 1856).

Irene, la protagonista de la tercera historia, llegará hasta Tijuana en 1987 para recomponer la vida de su madre y de su abuela: «¿Quién iba a decirme que sería aquí, en Tijuana, donde encontraría la punta de madeja de mi propia historia? [...] El azar es sorprendente» (Lorenzano, 2015: 209). En una arquitectura temporal hecha de conexiones fortuitas y reencuentros folletinescos, Irene descubrirá pocas semanas después de la muerte de Rita Hayworth que en el restaurante al que acude en busca de respuestas existe una fotografía de la dueña del local, la vieja Anette, junto a su abuela Claire. El reconocimiento será inmediato: la abuela de Irene, que murió siendo aún muy joven, era la hermana de aquella anciana del restaurante París, que todavía cada 30 de agosto celebra el aniversario de su hermana muerta en circunstancias espantosas. La vieja Anette relatará, entonces, a su sobrina nieta la historia que de por sí sola es incapaz de recomponer: la muerte de los padres en París, la llegada a México engañadas por un cura, el matrimonio de Claire con Norberto Cruz, el secuestro de Claire para ser prostituida por su

5 Discurso pronunciado en la fiesta de aniversario del People's Paper. 
propio marido, la inyección de morfina para soportar el dolor y, finalmente, la muerte durante el nacimiento de Noëlle, madre de Irene. De este modo, Irene sentirá que esa historia que había heredado con demasiados vacíos se completa ahora con el testimonio de Anette y restituye la genealogía familiar para proyectarla sobre sus hijos:

Me siento desolada por esa historia de desgarramiento que es también la mía, Juan. Desolada, y a la vez tranquila; conozco ya la memoria que heredaré a mis hijos, la que cubrirá los vacíos de es el? huipil que tal vez algún día yo también borde. Desolada, pero completa. Como mis mujeres, tengo ahora todos los hilos en la mano y me aferro a ellos (Lorenzano, 2015: 229).

Tijuana como el límite fronterizo entre la infancia y el trauma, entre el placer y el delito, entre la diversión y la agresión. En esa frontera física, ética y simbólica confluirán las tres historias ancladas en tres marcos temporales distintos: desde los años veinte hasta los años ochenta; confluirán las historias de Rita Hayworth, de Anette y de Irene; y confluirán sus respectivos conflictos: los traumas del pasado, la niñez prostituida, la violación del cuerpo de la mujer, las esperanzas frustradas, la pérdida de la memoria y la necesidad de elaborar una identidad propia y familiar.

\section{FRONTERAS DE LA MEMORIA}

En un trabajo a medio camino entre la neurociencia y la historia cultural, Enric Novella (2016) situaba la problemática de la «identidad» en los albores de la Modernidad:

un aspecto central en relación con la problemática de la identidad reside en su indudable historicidad. En este sentido, Bauman señala incluso que, en realidad, no es que la identidad se convirtiera en un problema con la irrupción del mundo moderno, sino que como un "invento específicamente moderno", ya "nació como un problema", esto es, como una tarea insoslayable y perentoria de 'construcción' que consagró simultáneamente la libertad de elección de los individuos y su dependencia de la guía y el consejo de expertos. Por su parte, Charles Taylor se ha interrogado por los orígenes y el desarrollo de la identidad moderna no tanto como un requerimiento o proyecto individual, sino como un patrimonio compartido y articulado en torno a una determinada cultura moral (Novella, 2016: 35). 
La identidad sería, entonces, la combinación de distintos elementos prototípicamente modernos: una creciente atención al yo, la necesidad de visualización de la sociedad de una determinada manera y la adecuación a distintos roles éticos o morales:

Así, su adquisición incluye el compromiso con ciertos roles, un sentido de continuidad y coherencia personal a lo largo del tiempo y de distintas situaciones, un sentido de agencia interna y cierto reconocimiento de los roles asumidos y de la visión de uno mismo por parte de la comunidad o los otros (Novella, 2016: 36).

De este modo, por su incapacidad de relacionar imágenes del pasado con el presente o de almacenar recuerdos o nombres, el desorden psíquico que conlleva el alzhéimer produciría un quiebre identitario de carácter patológico. En ese retiro en la Patagonia argentina, Rita Hayworth acumulará imágenes de su infancia, terrores antiguos, caras conocidas, escenas de películas, diálogos memorizados y fantasmas de la memoria en un torrente discursivo desordenado que hace que los niños de Puerto Madryn huyan despavoridos ante su figura gritando que la Lady está loca:

Lo único que quería era estar contigo y con mamá en la casa de Chula Vista. Que nadie te toque. Quedarme sentada en el porche mirando la nada. Pero a las cuatro de la tarde, papá sacaba el coche y me hacía señas. Era la hora de cruzar la frontera y cumplir con el trabajo del día. [...] ¿Cuándo empezó a pensar que mi piel era una extensión de la suya? ¿Que sus deseos tenían que ver con mi cuerpo? Yo no dormía, Veny. Pasaba la noche temblando bajo las sábanas, esperando ese instante atroz de la madrugada en que escuchaba cómo se abría la puerta de nuestro cuarto. ¿Tú también los oías, verdad? Re-cordis. ¿Quién quiere volver a pasar por el corazón su vida entera? (Lorenzano, 2015: 106).

La rememoración de la infancia y de los abusos sexuales acabará insertándose en un discurso lírico y delirante, reflejo del desorden psíquico de la protagonista en el que el lector ya no es capaz de seguir la representación del pasado sino a través de sensaciones, imágenes ambiguas e intuiciones a partir del habla de la estrella de Hollywood:

Los niños gritan: la lady está loca. ¿Qué saben aquí en el fin del mundo? ¿Qué saben frente a este mar gris, oscuro? ¿Qué saben frente a este viento 
afilado? La lady es la diosa del amor, les digo. Es la que regala su nombre a las bombas, La que está en los cuarteles. La que duerme pegada a la piel de los soldados. ¿Quién de ellos no ha sonreído imaginando que es a mí a quien toca? "Es una bruja". Las palabras de una lengua que me lastima. "Baila, Maggie, baila". Los pies sangran. ¿Por qué me mandas estas fotos viejas, Verny? ¿Qué son esos cuerpos? ¿Quiénes son los que me miran desde un blanco y negro desteñido? (Lorenzano, 2015: 217).

Pero no solo la patología opera un quiebre en la identidad. En el caso de Anette, la pérdida de su hermana Claire, la muerte de sus padres, el paso por México DF, León y Tijuana y la temprana acogida de sus padres adoptivos Martín y Adela dificulta toda elaboración del relato del yo. «¿París? ¿Qué sabía ella de París? [...] París era la bruma que cubría su infancia» (Lorenzano, 2015: 15). La frontera infranqueable más allá de esa bruma de su infancia, junto a la ausencia de sus seres queridos y de materiales con que reconstruir sus pasos, significa para Anette la desvinculación de todo origen y la incapacidad de determinar una identidad fija: la "francesita" que apenas pronuncia las erres, la huérfana, la engañada por Aguiar y Cruz, la abandonada en el Colegio de las Hermanas Mínimas en León, la regente del restaurante en la frontera con los Estados Unidos. Anette conserva retazos de su vida en Francia, del viaje en barco hasta América, del sufrimiento de su hermana al ser prostituida... y todos esos retazos regresan al presente con un sentimiento de culpa nunca restañado por la vida construida a lo largo del tiempo, ni tampoco por las explicaciones dadas a Irene una vez se reencuentran:

Todavía se me aparecen por las noches Aguiar, Norberto Cruz y hasta el médico que le inyectaba morfina a mi hermana para que su cuerpo siguiera aguantando los abusos y la violencia. La culpa es una daga que tengo clavada desde entonces; desde hace casi ochenta años. ¡Debí salvar a Claire y no lo hice! (Lorenzano, 2015: 229).

Por su parte, Irene sentirá el mismo quiebre identitario que Anette por no saber quién fue su abuela Claire, ni de dónde vino, ni qué fue de ella. La última frase que pronunció esa abuela misteriosa, «somos las guardianas de la memoria» (Lorenzano, 2015: 19) según le contó su madre, empujará a Irene a buscar respuestas al misterio familiar. Esa búsqueda la iniciará días después de la muerte de su madre, Noëlle, y al enfrentarse a las cajas y armarios de la casa familiar, de donde afloran papeles, fotos recuerdos sin árbol genealógi- 
co al que encaramarse. Al vaciar la casa para hacer lugar a nuevos habitantes y simbólicamente a nuevas generaciones, la protagonista entiende que no tiene una historia que dejar en herencia a sus descendientes, que existe un vacío perentorio que debe llenar, que de algún modo esos papeles y fotografías la interpelan para que busque, les otorgue un sentido y las inserte en un relato familiar. «¿Quién era Claire, mamá? ¿De dónde venía? Hace cincuenta años que creo que la foto de la llegada a Veracruz es lo único que tenemos de ella, y ahora aparece esto. Tengo la cartilla de sanidad en mis manos y de pronto se enredan los hilos de nuestra historia» (Lorenzano, 2015: 111).

El único de los tres personajes que logra franquear la frontera de la memoria con éxito será Irene, al completar la memoria familiar heredada con la memoria personal de Anette. Para Halbwachs $(1968)^{6}$, toda memoria individual se inserta en unos marcos sociales que no tienen solo un carácter histórico o nacional (memoria histórica), sino que tienen la mayoría de las veces un carácter familiar o sentimental, que genera del mismo modo una identidad colectiva a un grupo concreto de personas. Solo Irene puede completar este proceso y sentirse identitariamente unida a una estirpe: «Sé que soy de esa estirpe. Aunque se me enreden los hilos del bordado, esa es mi herencia. Eso tengo que darles a María y a Santiago. Algún día será lo que dejaré a mis nietos» (Lorenzano, 2015: 176). En cambio, Rita Hayworth no logrará completar tal proceso, pero tampoco Anette, quien se limitará a transmitir la mitad de su historia a Irene. Ya en su novela anterior, Fuga en mí menor (2012), Sandra Lorenzano abordaba la problemática epistémica del individuo a partir de la ausencia del padre, y la problemática identitaria del exilio y el desarraigo (González Luna 2014); en esta novela Leo intenta recuperar los restos de su padre Giulio, partisano fusilado por los nazis en un monte de la Toscana, y averiguar quién fue aquel hombre. Solo a partir de la asunción del silencio, de la imposibilidad de conocer y de la validez de los textos de Cesare Pavese

\footnotetext{
6 "En muchas novelas que describen el destino de una familia o de un hombre apenas importa que sepamos en qué época tienen lugar los hechos: no perderían nada de su contenido psicológico si se los transportara de un período a otro. ¿No se intensifica la vida interior en la medida en que se aísla de las circunstancias exteriores, que son las que ocupan un primer plano en la memoria histórica? Si más de una novela o de una obra de teatro son situadas por sus autores en un período varios siglos alejado del nuestro, no es las más de las veces sino fruto de un artificio que busca dejar de lado el marco de los acontecimientos actuales y hacer sentir mejor hasta qué punto el juego de los sentimientos es independiente de los hechos de la historia y se parece a sí mismo a través del tiempo. Si por memoria histórica se entiende la lista de los acontecimientos cuyo recuerdo conserva la historia nacional, no es ella, no son sus marcos los que representan lo esencial de lo que llamamos memoria colectiva" (Halbwachs 1968: 212).
} 
y de las músicas de Bach y Mahler como elementos afiliativos del hijo, podrá elaborar el duelo de la muerte del padre.

Solo quien recupera la memoria o quien es consciente de su imposibilidad frente a ella es capaz de escribir y de enfrentarse a una última frontera más allá de la realidad: la frontera del lenguaje.

\section{FRONTERAS DEL LENGUAJE}

Irene comienza su relato un 15 de mayo de 1987, el día después de la muerte de Rita Hayworth, en primera persona y a modo de diario. Junto a ese relato en primera persona, la estrella de Hollywood desata en paralelo un flujo de conciencia en el que las películas se mezclan con los recuerdos y los nombres y caras se pierden en la bruma de la memoria. Junto a estos dos, en tercera persona se relata la historia de las hermanas Claire y Anette, desde su viaje a México, hasta la muerte de la hermana mayor y los avatares de la pequeña. Si bien Rita Hayworth emplea un procedimiento de "rememoración" para intentar no morir sin saber quién es realmente, podemos decir que Anette inicia su relato del pasado a partir de la "revelación" de la existencia de Irene; y a su vez Irene emprende una búsqueda a medio camino entre la "reconstrucción", apoyándose en fotografías y papeles de su madre, y la "investigación", organizando toda esa información y yendo en busca de la hermana de su abuela para completar la historia familiar ${ }^{7}$. En cualquier caso, desde distintas perspectivas se intenta indagar en el pasado personal o familiar y dar respuesta a preguntas fundamentales: quién soy, quiénes son o quiénes eran, muy en la línea de las novelas de investigación de escritor a ambos lados del Atlántico (Martínez Rubio 2015). Toda búsqueda, una vez manifestados los límites del conocimiento, se enfrentará al problema de cómo contar: cómo contar desde el alzhéimer, desde una memoria que se diluye con el avance de la enfermedad; cómo contar desde la ausencia y desde la culpa; cómo contar desde los interrogantes de unas fotos y unos papeles.

\footnotetext{
7 Para un análisis de las distintas categorías de indagación: rememoración, reconstrucción, revelación, exploración e investigación; cfr. Martínez Rubio, José (2013): «La ricerca incessante. Cinque procedimenti di indagine nella cultura ispanica contemporanea: da Bolaño a Brizuela». Pagine inattuali. Roberto Bolaño dieci anni dopo. Una retrospettiva, n. 3, Napoli. pp. 159-185; o bien Martínez Rubio, José (2015): Las formas de la verdad. Investigación, docuficción y memoria en la novela hispánica, Barcelona, Anthropos.
} 
El relato que se nos presentaba como veraz ante el lector (el de la biografía de Rita Hayworth) se torna inaccesible, pues el testimonio de la protagonista está anulado por la enfermedad del alzhéimer; paradójicamente, la literatura vendrá a poner palabras a esa imposibilidad de resituar una identidad en suspenso.

Solo quien es capaz de recuperar o comprender, decía anteriormente, es capaz de contar. Será Irene, desde su completud una vez encuentre a Anette, la que emprenda el trabajo de escritura. Junto a ese diario dirigido a una segunda persona, aparecerá el monólogo de Margarita Cansino y la historia de las hermanas francesas, como complemento de su propia historia, como vidas paralelas (en otro espacio y en otro tiempo) que otorgan unos significados que perfilan y completan su propio relato, que insisten en el conflicto consigo misma a raíz de la muerte de la madre: quién soy, quiénes son mis ancestros, qué historia dejaré en herencia a mis descendientes. Para que Irene pueda completar su historia, las hermanas francesas, víctimas de la explotación y de la miseria que genera en sí la Modernidad, se habrán quedado sin relato propio, a merced del olvido y a merced de alguna guardiana que intente a duras penas conservar esa memoria. Por su parte, Margarita Cansino concentrará en una imagen patética, la de la anciana enferma de alzhéimer hablando sola frente al mar, la incapacidad de anudar un relato certero y estable sobre sí misma. La posibilidad de dar una respuesta por parte de Irene restituirá la idea de "estirpe" pero pondrá en cuestión que esa estirpe sea, una vez más o al menos por una vez, la estirpe del silencio.

\section{BIBLIOGRAFÍA}

BERMAN, Marshall (1988), Todo lo sólido se desvanece en el aire. La experiencia de la Modernidad, Madrid, Siglo XXI.

Bolaño, Roberto (2004), 2666, Barcelona, Anagrama.

Cravey, Altha J. (1998), «The New Model, A Case Study of the Maquiladora Industry», en Women and Work in Mexico's Maquiladoras, Lanham, MD, Rowman and Littlefield Publishers. 
GonZÁlez LunA, Ana María (2014), «Exilio y búsqueda del padre en Fuga en mí menor de Sandra Lorenzano», Altre Modernità, Rivista di studi letterari e culturali, 2, págs. 79-92.

GonZÁlez Rodríguez, Sergio (2002), Huesos en el desierto, Barcelona, Anagrama.

Halbwachs, Maurice (1968), La mémoire collective, París, PUF

LorenZano, Sandra (2015), La estirpe del silencio, México, Seix Barral.

- (2012), Fuga en mí menor, México, Tusquets Editores.

Martínez Rubio, José (2013), «La ricerca incessante. Cinque procedimenti di indagine nella cultura ispanica contemporanea, da Bolaño a Brizuela», Pagine inattuali. Roberto Bolaño dieci anni dopo. Una retrospettiva, n. 3, Napoli, págs. 159-185.

- (2015), Las formas de la verdad. Investigación, docuficción y memoria en la novela hispánica, Barcelona, Anthropos.

Novella, Enric (2016), «Subjetividad expresiva y patología de la identidad», en Martínez Rubio, José; Enache, Irina; Lakhdari, Sadi (eds.), Identidades inestables. Avatares, evoluciones y teorías de la subjetividad en la narrativa española actual, Paris, Harmattan, págs. 29-46.

PoniatowsKa, Elena (2002), «Ciudad Juárez, matadero de mujeres», La Jornada, 26/11/2002

«Rita Hayworth muere a los 68 años, de una enfermedad del cerebro», $E l$ País, 16/05/1987. Disponible en: http:/ / elpais.com/diario/1987/05/16/ cultura/548114403_850215.html

«Rita Hayworth murió sin saber quién era», EL Tiempo, 24/09/1994. Disponible en: http:/ / www.eltiempo.com/archivo/documento/MAM-226527

«Rita Hayworth, Movie Legend, Dies», New York Times, 16/05/1987. Disponible en: http://www.nytimes.com/learning/general/onthisday/ bday/1017.html 
